\title{
Peer-learning: An Alternative Teaching Pedagogy for Highly Teacher Centered Classes
}

Karma Utha ${ }^{1}$, Sangay Rinzin ${ }^{2}$

${ }^{1}$ Department of Science Education, Samtse College of Education, Royal University of Bhutan, Bhutan

${ }^{2}$ Freelance, Samtse, Bhutan

\begin{abstract}
The present study was undertaken to find out whether peer learning can be an alternative teaching pedagogy in a highly teacher centered class taking Bhutanese school as case study. The study involved classroom observation of teaching and learning processes and focus group interviews. The study sample included 11 Bhutanese secondary schools spread over 4 Dzongkhags (state). 22teachers and 88 students were engaged in the study.

One of the main findings of this study is the minimal existence of comfort zone between the teacher and students in Bhutanese schools. This has led to the practice of peer learning initiated both by the students and teachers to enhance students' learning. Another finding is that peer-teaching is a dominant practice as compared to reciprocal peer-learning. Other findings include the existence of opportunities to enhance peer-learning through remedial classes and in boarding schools.

Some of the recommendations are: to include the peer learning method with its multifaceted approach as one of the teaching and learning approaches in teacher training programmes; implement peer learning through remedial classes and in hostels; and work towards the comfort zone between the teacher and the students.
\end{abstract}

Keywords-Peer-learning, peer-teaching, reciprocal peer-learning, comfort zone, boarder, day scholar.

\section{INTRODUCTION}

The education system in Bhutan has seen lots of positive changes in the last few years. It has now in place educational policies, curriculum frameworks, Bhutanese-based curriculum, the use of teaching-learning approaches that are found effective in schools worldwide, and segregated teacher training programmes for primary, secondary and University level teaching, continuous professional development programmes for teachers, and facilities in terms of improved infrastructure. Besides, the schools now have mostly Bhutanese teachers only having initially depended upon teachers from India (Schuelka and Maxwell, 2016). All these are meant to enhance students' learning outcomes. However, the cultural values and practices that were found to impact the ways students learn in some south Asian countries (Loh and Teo, 2017; Kyong-Jee and Curtis, 2002) is also having an impact on the way Bhutanese students learn.

In almost all the Bhutanese schools, the teaching and learning approach is still teacher centered(Maxwell, 2008). The teacher's authority is respected and everything given in the textbook and taught by the teacher is followed without much question. The emphasizes on 'respect of elders' is found to play a major influence in the classroom culture (Roder, 2012; Utha, 2015, Utha et al, 2016). For example, Roder in her $\mathrm{PhD}$ dissertation has pointed that in the classroom, a teacher is always looked upon as someone whose knowledge cannot be questioned. He or she is supposed to have an answer for every question. As such a high regard is placed on the teacher. In the class, students generally maintain silence when the teacher is teaching and nobody would dare to intervene or make direct eye contact (2012). Further, Utha (2015) pointed that the students hardly ask questions to teachers even when in doubt. If the teachers ask questions, usually no student would volunteer to answer or give chorus answer. If individuals are pointed to answer, the class becomes very quiet. It is only a few high achievers volunteering. In urban schools, some positive changes are taking place in terms of students asking questions to teachers but such practices still have a long way to go. Maybe the influence has passed on from monastic education as education in Bhutan started there (see Schuelka \& Maxwell, 2016).In monastic education, faith and devotion was 
bestowed to the teachers and the religious texts and the teacher's authority prevails without question (Utha, 2015).

Use of teacher centered teaching approach was found in Chinese schoolswhere students tend to be dependent learners relying on their teachers to provide content materials thereby being passive learners (Loh and Teo, 2017) which was also found in Bhutan. However, Utha had pointed out observing two practices in Bhutanese schools. First, high achievers were helping low achievers. Second, in pair or group work, a high achiever was usually paired up with a low achiever (2015). This was associated with peer-learning. However, literature studies did not really point to implementing peer learning as a teaching learning strategy in teacher centered classes. Hence, this study was aimed to find out the extent of use of peer learning in Bhutanese schools and its effectiveness on improving students' learning. Further, it will study whether peer learning could be an alternative teaching approach in ahighly teacher centered class.

The findings of this study would be beneficial to others working in similar context especially the Asian countries. Besides, it will provide evidence based information to teachers and Ministry of Education at large in reviewing their educational policies to enhance students' learning. The findings will also be useful to the teacher training colleges of Royal University of Bhutan and others to make informed decisions on the type of pedagogical practices taught as part of teacher preparation.

\section{LITERATURE}

Peer learning, according to Boud, Cohen and Sampson, refers to the use of teaching and learning strategies in which students learn with and from each other without the immediate intervention of a teacher $(1999$, p. 413, italics in original). Similarly, Topping (2005, p.631) has defined peer learning as the acquisition of knowledge and skill through active helping and supporting among status equals or matched companions. It involves people from similar social groupings who are not professional teachers helping each other to learn and learning themselves by so doing. It is said to be practiced where the teacher is required to teach large student numbers due to Universities' financial difficulty (Boud, 2001,P.11). Besides peer-learning is given a priority in education system as increasingly employers look for graduates with transferable skills like team spirit, communication skills, open to criticism, being able to articulate what one understands, and have self-management skills which are learnt through it.

Peer learning is broadly classified asReciprocal peer learning and peer teaching. Learning among friends need not necessarily be taking place from only one high achieving student to a low achieving student. In fact, reciprocal peerlearning takes place whereby each student teaches the other and the learning happens in a mutually accepted positive interdependence. It occurs between same ability students whereby each act as both teacher and learner. Peer teaching is practiced by teachers as well as students themselves by forming a kind of social grouping amongst, for example, low achiever and high achiever students whereby the high achiever student takes on a limited role of teacher and low achiever takes on the student role. The high achiever students may be from the same class or those in later years (Boud, Cohen and Sampson, 1999, p.414). Between reciprocal peer learning and peer teaching, the latter is a found to be practices more in many universities, whereas reciprocal peer learning is often considered to be incidental - a component of other, more familiar strategies, such as the discussion group (Brookfield and Preskill 1999 in Boud, 2001).

The peer learning serves as an important source of timely feedback to all the participants. According to Wessel (2015, p.14), when students engage in peer tutoring (a term used for peer-teaching), they are able to learn practical skills in how to teach and give critical feedback. The students also learn how to engage in learning that is not strictly teacher-led, and they can engage more in the dialogue and topic questions to help with clarification. Peer tutoring can help to promote children's natural abilities in context with their learning. Peer learning has been proved to be one effective teaching and learning strategies whereby students are active and positive, and teachers are facilitators rather than being the source of knowledge (Sukrajh, 2018;Mustafa, 2017). In general, peer tutors help other students either on a one-to-one basis or in small groups by continuing classroom discussions, developing study skills, evaluating work, resolving specific problems and encouraging independent learning (Arrand, 2014). The teachers are being there to answer questions and help prompt discussion (Wessel, 2015, P.14). Though learning was enhanced through peer-learning, there were small section of students in medical fields who preferred learning from teachers as peers may not reflect the knowledge of an experienced expert in the field (Butle, Betts, Garner \& During, 2007). 
For peer learning to take place, a formal grouping is not required even though group work is said to involve peerlearning (Jaques, 2000). For example, in a study conducted by Hakizimana and Juegens in 2013 in schools in South Africa and China, the teachers make the sitting arrangement in the class in such a way that a weak and a better performing student would be sitting next to each other. This kind of sitting arrangement in fact is looked on by a teacher as an advantage to both the weak as well as better performing student (Utha, 2015). In addition, peer learning need not necessarily take place face to face. With internet facilities, it is observed to be frequently used in distance courses via email (Boud, 2001, p.18). The Online interaction is found to be used by students who according to Yang and Chang (2012) are too shy to raise their voice in front of the large number of students in the lecture hall, some might find themselves wondering if their question isn't too stupid to be asked publicly.

Peer learning initially was practiced in subjects like reading and mathematics only. Later, it was practiced in spelling and writing, science, and other subjects which require thinking skills. But now due to its effectiveness, it has taken hold in college and university education and has been applied to wide range of subjects (Topping, 2005;Boud, Cohen \&Sampson, 1999). Peer learning is also found to be effective for students with special needs (Scruggs \& Mastropieri, 1998 in Topping, 2005). However, Boud has pointed out that if peer-learning approach is not familiar to students, they get confused about what they are supposed to do thereby missing opportunities for learning and failing to develop the skills expected of them (2001, p. 9). Similarly, other researchers emphasized that for peer learning to be effective, the student tutors should be provided with instructions and guidance beforehand on how to effectively teach quality material to others (Wessel, 2015, p.14; Ross \& Cameron, 2007in Sukrajh, 2008). In the case of student tutoring, the tutors need to have some accelerated level of knowledge in the content area so they are able to effectively tutor the other student. Effective peer learning strategies also depend on the children's level of learning. Young students have a hard time discussing and interpreting issues and topics, so for peer learning to be most effective, it should be implemented with older children, perhaps starting in late elementary and early middle school years (Topping, 2005).

Overall, students feel more comfortable saying things to each other when the teacher is not around. They add more to the conversation because they are not as intimidated as they are when they have to answer a teacher's question or address the large group (Wessel, 2015).Routman(2005) states that students learn more when they are able to talk to one another and when they are actively involved in their own learning. The comfort level amongst the learners is high as the communication is usually in the language they are at ease with (Sadler, 1998; Black et al, 2003; Black \&Wiliam, 2005; Clarke, 2005; Topping, 2009). The students feel less threatened and are able to admit to ignorance and misconceptions which can be corrected and creates better understanding (Topping, 2005). Students engage in deeper learning with peers as they form relationships which allows them to freely explore concepts, learn to listen and critique each other without the presence of authority (Boud, Cohen \& Sampson., 2001).

Per learning especially peer teaching is often used in remedial courses to cater to the needs of students who are unable to progress with the class in a normal classroom (Abu Armana, 2011). Cheng (2014) cited that remedial teaching must assist students to consolidate basic knowledge, master their learning strategies, strengthen their confidence and increase the effectiveness of their learning. Various studies have shown that students who received remedial teaching had enhanced learning compared to others who did not (Cheng, 2014; Jadal, 2012; Abu Armana, 2011; Luo, 2009). With appropriate and additional help, low-achievers' learning difficulties can be identified to provide further scaffoldings.

\section{METHOD}

The research design for the study was qualitative. It was carried out by employing classroom observationand focus group interviews. Classroom observation was carried out to observe the teaching-learning processes as it happens, and record the interaction taking place between the teacher and the students and amongst the students themselves, and the existence of the comfort zone. The focus group interviews with students and teachers respectivelywas intended to get an understanding of:(1) students' and teachers' use of peerlearning practices; (2) the type of peer-learning approach that is most applicable in the Bhutanese schools;and (3) the effectiveness of the practice in enhancing the students' learning outcomes.

The study was carried out in 11 secondary schools under fourdzongkhags (states): Samtse, Chhukha, Paro and Thimphu in the east of Bhutan. The choice of the dzongkhagswas based on the proximity of the researchers' work area. The choice of the schools was based on ruralurban setting and boarding and day school. This was to gain a rich and wide variety of data material to get a clear 
understanding of the peer-learning practices. The informants for this study consisted of students from Middle Secondary and Higher Secondary classes (classes VII to XII) and teachers involved in teaching these classes. The classes are so chosen as the literature study points to peer-learning being effective for students in the late elementary or early middle secondary (Topping, 2005). Also, the researcher is currently based in a teacher training college that is mandated to train teachers who will be engaged in teaching students of these classes.

In each school, two classroom observations were carried out to get an understanding of peer-learning process as it happens. The classroom observation of teaching and learning process were carried out either on voluntary basis or based on school nominee. A total of eight classroom observations were conducted. After each classroom observation, focus group interview was conducted with the two teachers engaged in teaching the observed classes. A total of 22 teachers were interviewed. A focus group interview was also carried out with six to eight students, with equal representation from each classes observed. There was equal representation from both male and female students and teachers. The selection of the students for focus group interview in each school was carried out by the two teachers from the respective schools who were engaged in the interview.

Before the start of data collection, prior permission was obtained from each dzongkhag's Chief District Education Officer. Approval was also sought from each school Principal. For each of the classroom observation and interviews, the participants' approval was sought. Since the interviews were voice recorded, approval for it was also gained from respective interview participants.

\section{DATA ANALYSIS}

The interviewed data were transcribed verbatim. The classroom observations were recorded in the form of notes. The transcribed data and classroom observation notes were studied in depth noting any word or sentences that were found to be interesting and considered as solid findings. The words or sentences were then grouped to form themes, that is, a thematic analysis was employed across the two data sets.The themes generated as a result were:peer-teaching, reciprocal peer-learning, comfort zone, andteaching-learning support.

\subsection{Peer-teaching}

In all the schools under study, two forms of peer-teaching were observed. One was the student initiated peer-teaching whereby students formed a group among themselves based on their own mutual understanding. Second was the teacher initiated peer-teaching in which the group choosing of the group members were carried out by the concerned teacher.

\subsubsection{Student initiated peer-teaching}

The student initiated peer-teaching was normally initiated by the students who did not understand or partially understood the concept the teacher taught (all FGSs). It mostly took place during the students' recess time (FGS4; FGT10). The students who had not understood teachers' teaching sought support from those students who according to them were the high achievers in that particular class (FGS7; FGS8; FGS9; FGS10), or senior students(FGS4; FGS8; FGS11). However, one focus group students mentioned that before approaching other students for clarification, they read through what was taught and referred the textbooks. After that if they still had doubt than they approached other students (FGS4; FGS11). In this kind of setting, most of students said that they were able to understand when others explained (all FGSs). However, three focus group students mentioned that there were times when even the high achievers were not able to clarify the doubts (FGS7; FGS4; FGS9). In such case, they approached the student who according to them was the section high achiever (in each school, students of same class would be divided into many sections). If the section high achiever was not able to clarify their doubt, then they formed a group and approached the teacher for clarification. Sometimes, they kept the questions in the parking lot (term used by the school for questions to be asked to teachers after normal school hours) which was later collected by the teacherand clarified (FGS7). However, teachers would normally be the last person students would approach for clarification (FGT10; FGS4).

\subsubsection{Teacher initiated peer-teaching}

Almost all the focus group students agreed that teaching was mostly teacher directed. There were many times when whatever was taught was not clear to students. They cited three reasons: teaching was very fast, only notes were given and teacher did not explain what was given in the notes, the teaching was mostly teacher directed (FGS8, FGS9). The practice of students asking teachers to explain again if the concept being taught was not clear was almost non existent (FGS9). However, when the teachers asked whether they have understood, they usually said they have (FGS1; FGS2; 
FGS6; FGS8; FGS9; FGS11). But in most instances, the teachers were aware of such practices (all FGTs). The teachers cited large class size of about 40 students each and huge syllabus to cover as some of the reasons for carrying out teacher directed teaching and learning practices (FGT9, FGT10, FGT11). During such times, the teachers mentioned using peer-teaching. They formed a group among students consisting of a high achiever and a low achiever(s). The high achieving students were then asked to help the others (all FGTs) which were evident from interview extracts:

Sometimes there are some categories of students who do not understand when teacher teaches but when [a] friend teaches that same concept in their level, they understand. So, that is done because one good learner is kept there. I encourage that. I always tell in the class also that 'I understand some of you may not be understanding my way of teaching but because I am the teacher that is not the reason to stick on. You can always ask the person who has understood'. I always encourage that (FGT2).

For example, if I have to spend 50 minutes of teaching, I have to concentrate on syllabus. If I keep on spending 15 minutes to every student in the class, then it might take me whole day to complete the required syllabus. That's why I feel that sometimes for students it's better to learn from friends to understand the lesson. (FGT10)

In most of the school, to cater to the learning needs of a weak student, the classroom sitting arrangement was arranged in such a way that a better performing student was paired with a weak student (FGT1, FGT4). This was apparent from a teacher's remark:

When I teach them and get vague answer, I tell them to get into pairs as the class is already divided into pairs (sitting arrangement) i.e. one good and one weak and tell them to learn from each other as what one knows, other may not know (FGT1).

On the issue of disparity that might come with this kind of sitting arrangement, a teacher justified that students were not informed on how the sitting partners were chosen:

There are advantages as well as disadvantages. A[n a]dvantage is that they will learn and [a] disadvantage is that they will be demotivated but as a teacher, I don't tell that good student will sit with [a] weak student. I make in such a way that they do not know that one is good and other is weak (FGT1).
There was also one case of using threat in the teacher initiated peer-teaching. In one focus group, a teacher said that students were not only informed on how the sitting arrangement was carried out but the high achiever students were informed that they would be punished if their sitting partners did not show improvement in studies (FGT4). One students from the same school said that it was difficult to bring improvement if some one was not really interested in studies (FGS4). However, the data did not indicate of using any punishment by the teacher.

Most of the students confirmed that they were aware of these kind of sitting arrangement (FGS1; FGS4; FGS10). A student stated that they respect the arrangement carried out as the teacher would have a good intention for the students (FGS10).

On the usefulness of peer-teaching, all the students and teachers in the focus groups agreed that most of the time, learning was effective. A majority of the students said that they understood better when friends explained (FGS9; FGS4; FGS6; FGS3). One focus group students mentioned that not only the low achieving students but also the high achieving students benefit from such practices. The low achieving students clarify what was not understood and the high achieving students get to revise what they already knew and make their understanding clearer (FGT4, FGT10). Nevertheless, there are couple of students who prefer learning mostly from teachers only (FGS9; FGS8). These were the students who were performing comparatively better in studies and according to them, they understood whatever the teacher taught.

There was also one case of using threat in the teacher initiated peer-teaching. In one focus group, a teacher said that students were not only informed on how the sitting arrangement was carried out but the high achiever students were informed that they will be punished if their sitting partners did not show improvement in studies (FGT4). One students from the same school said that it was difficult to bring improvement if some one was not really interested in studies (FGS4). However, the data did not indicate use of any punishment by the teacher.

\subsection{Reciprocal peer-learning}

The study revealed practices of students undertaking reciprocal peer-learning whereby a group of two or more students undertook the responsibility of teaching and learning (FGS5; FGS8; FGS11). In such grouping, there were no mention of high achiever and low achiever. It took place among students of almost same learning ability. In 
thispractice, each student took turn to explain the concept (taught by the teacher) they had understood to the ones who had not understood (FGS5; FGS6; FGS8; FGS11). This practice was not confined to only one student clarifying the doubts to other. Each student in the group took turns to explain what they have understood to the rest of the group members. This was evident from the citation of one student: "What we don't know, they may be knowing and what they don't know, we may be knowing. So we can feel [free] to ask to them [our doubts] and [they ask] their doubts to us" (FGS6).

Teachers were also found to encourage such learning. For example, in two schools, there was a practice of forming a pair called 'buddy learning' (FGT8) and 'reading partner' (FGT9). In such cases, one student took on the role of a teacher and another a reader. According to a teacher, when one student was reading, the other would point out and correct the mistakes made in pronunciation (FGT9). This process was repeated with student changing the role of reader and teacher. Similar practice also happened when the students were given group work by the teachers. Within the group, task for each individual was divided (FGS3). After the task was completed, each student took turns to explain what they have found.

The study revealed that though reciprocal peer-learning took place, the practice was not as widely used as peer-teaching. Students and teachers of three focus group confirmed that the practice was not as prominent as peer-teaching (FGS8, FGT10, FGT8). It was also evident from the study that the term 'reciprocal peer-learning' was not familiar to the teachers as well as students (all FGs). When the researcher asked the focus group students and teachers in each school on the type of peer-learning undertaken by them, the term 'reciprocal peer-learning' was never mentioned (all FGs). However, when the term was explained by the researcher, most of the focus groups confirmed that such practices took place sometimes but that they were not aware of the terminology being used. An excerpt from the interview was self-explanatory:

Interviewer: There is a teaching learning strategy called as peer-learning. Literature study has explained that peer-learning is of two types: peerteaching and reciprocal

peer-learning. In peer-teaching, a student takes on a limited role of teacher and teaches the weak student. In reciprocal peer-learning, two students of almost same ability teach each other. Madam has explained that peer-teaching does take place in your class. Do you also practice reciprocal peer-learning?

Teacher: Now I understood exactly what peer learning and its types are. That is in fact happening. Even if it is not happening in school, but I think outside it is happening. (FGT9)

Similar exchanges between the researcher and other focus groups were observed in all schools under study.

\subsection{Comfort zone}

The study revealed that the extent of practice of peer-learning was due to the existence of comfort zone. Almost all the focus group students mentioned that they sought help from friends in clarifying their doubts. They mentioned seeking teachers support only if they ran out of any other means like asking friends and referring other books (FGS4; FGS8; FGS10; FGS11). Several reasons were cited as explained below.

From the study, the existence of comfort level among friends was quite obvious. Most of the students mentioned that they approached friends due to the high comfort level between themselves (FGS4, FGS8, FGS10, FGS11). A student said that with friends they could argue their point which was not possible with a teacher:

I feel uncomfortable with teacher. Friends are comfortable to us. With friends we can argue our points. We are at the same level and we tend to find their mistakes. But if it's a teacher, even if we have some doubts in our mind, we hesitate to say those things. But with friends we can clear out any doubts and argue with them. (FGS5)

The other reason cited was the feeling that the teacher would misinterpret their asking questions (FGS4; FGS8; FGS10). The following quote exemplifies:

The comfort zone makes us to approach our friends. If you don't understand and want to ask the teacher, you kind of feel that maybe the teacher will feel we are not listening. With our friends we can ask everything openly. We can even joke around. I think learning takes place better with friends. (FGS10)

Some of the students wanted to ask the teacher but the fear that the teacher would find their questions 'silly' (term used by a student) and ridicule them stops them from seeking teachers' help (FGS4). One focus group students commented that with friends they can ask the question again and again till the doubt was clarified which does not happen with the teacher (FGS10) 
The existence of the comfort level was also due to the language used in communication. With the teachers, students were expected to converse in Englishonly but with friends they usually communicate in their local dialect or the language they were comfortable with (FGS7; FGS10; FGS4; FGS11).

Another reason for students not approaching teachers for clarifying doubts was when the teacher was found to be quite strict (FSG1; FSG4; FGS8; FGS10) with some resorting to use of corporal punishment (FGS8, FGS10). This was evident from one of the interview excerpt:

Student: Usually I am very scared of teacher. So, in case of teachers who are lenient, I am able to ask the teacher but I feel I understand better when I ask my friend.

Interviewer: You just said that you are scared of the teacher. Is it something with the teacher that you are scared and not able to open up?

Student: Yes. Some teachers are scary. It seems like we are irritating them. Some teachers even tend to beat us. So, I am very scared of that. (FGS10)

This kind of fear of teacher was also evident in another interview:

Interviewer: Which is easier for you- asking teachers or friends?

Student: Friends because if I ask teachers they mostly they say that we don't listen and beat us.

Female student:I ask friends because I am scared of teachers. They might scold us as they think we are not attentive in the class. (FGS8)

Though the teachers being strict was mentioned in other focus groups too, the use of corporal punishment was not evident.

In general, all the teachers interviewed seemed to be quite aware of the issue of students not being able to understand everything they taught. All of them said that students hardly ask questions to them or approach them to clarify the doubts. However, none of them mentioned that it could be due to the level of comfort (all FGTs).

\subsection{Teaching-learning support}

There were broadly two kinds of living arrangement for students: boarding facilities (term used was hostel in the schools) or day scholar (living with parents or guardians or students living on their own in a rented house). The kind of learning support received in these kinds of arrangement varied.

\subsubsection{Boarding}

In this study, three schools had boarding facilities.In each, aboutten to twelve students shared a room. In two schools, each room had students from mixed classes. This arrangement according to the teachers was to encourage social interaction between students of different classes and also to minimize disciplinary cases (FGT7; FGT8). According to the students, this kind of room arrangement did not allow for much peer learning (FGT7). In the hostel, peer learning was taking place but it was minimal. The students confirmed that certain silent decorum had to be maintained in the hostel. Hence they were engaged in more independent study than in peer learning (FGS7, FGS8). In the school where students from same classes shared a room, peer learning rarely took place as again the hostel had rules on maintaining silence (FGS4).

In almost all the boarding schools, remedial classes were conducted. It was specially meant for only weak performing students but all students irrespective of their performance level attended. Also, some of the day scholars living nearby attended the remedial classes. Most of the teachers claimed that peer teaching happenedduring remedial classes (FGT4; FGT8). However, according to the students, it did not happen.Instead, the practice was said to be a study class where each student silently studied on their own and once in a while the teacher on dutyclarified students' doubts if it was his or her subject (FGS10; FGS11). In one school, students claimed that teachers used the remedial classes for teaching if they were behind in terms of syllabus coverage. The same students alsomentioned that in remedial class, peer learning was not encouraged as students made noise and disturbed the other students (FGS8). Also, the remedial classes were supervised by teachers in turn and they were usually called as teacher on duty (FGT4, FGT10, FGT11)

Boarders were not allowed to keep mobile phones with them. The schools had computer laboratories with internet facilities but students rarely had access to it after school hours (FGS4; FGS8). During the school hours also, students were given access only when they had IT class.

\subsubsection{Day scholar}

In this study, there were eight day schools. For the day scholars, the educated parents providedhelp in their learningdepending on their parents' education level and their availability. One student said, "my mother is educated but not that much educated. She is only good in Maths. So, I ask only Maths problem to her" (FGS9). There were cases when 
educated parents were engaged in other activities and not able to help their children. This wasillustrated by one student, "My mother is not educated and my father is busy all the time. So I teach myself" (FGS9).For those students who rent a house and live on their own, peer learning was not observed as they did not have friends living nearby (FGS1).

A difference was observed in terms of parental support to peer learning between students studying in urban setting and rural setting. According to the two focus group interviews conducted with students studying in urban setting, most of the students mentioned that theyhave certain restrictions put in place by their parents in visiting their friends' place for peer-learning (FGS11, FGS10). According to the lower secondary students (grade VII-VIII), they were usually not allowed to visit friends' houses. Their parents did not send them out as they were young and may land up playing instead of studying (FSG11). As per the more adult students (grade IX-XII), theirparents did not send them out for peer learning as their parents worried that they may get into unnecessary social problems (FGS10). However, some educated parents (who were working as teachers) support peer learning. They allowed their children to visit their friend's place but made sure to drop and pick them up within a time frame (FGT10). In the rural setting, students mentioned that their parents allowed them to visit friends' places for peer learning though their visit was limited due to proximity of their friends' houses (FGS4).

For day scholars, some teachers and students had initiated learning through use of social media (FGT11, FGT10). All the students said that they had access to mobile phones. They either possessedtheir own or used their parent's phone. They usedsocial media to exchange important information, notes and clarify questions. However, the practice was yet to stabilize.

\section{DISCUSSION}

In Bhutanese schools, pedagogical approaches in classroom teaching is still more inclined towards being teacher centered. However, students' learning was a concern for both teachers and students themselves. Both were actively engaged in taking learning forward through whatever possible means and one of it was peer learning in the form of peer teaching and reciprocal peer learning. Except for stray cases where high performing students preferred learning from only teachers, peer learning was generally found to be quite effective in enhancing students learning. It was also found to be beneficial for both the weak and high achievers which was in agreement with the literature findings (Sukrajh, 2018; Wessel, 2015; Mustafa, 2017).

Peer teaching initiated by students themselves and by the teachers was in line with the literature (Boud, Cohen and Sampson, 1999, p.414). The high achiever either from the same class or seniors normally took on a limited role of a teacher or taught the low achievers. In the student initiated peer teaching, the low achievers would approach the high achievers for support. The teachers were approached only when the high achievers were not able to clarify their doubts and during such times, students usually approached in groups.

Most of the time, students did not understand teachers' teaching but hardly voiced it to the teachers. Teachers though aware of such cases, expressed their inability to provide support owing to large student number and vast syllabus to cover. Hence, they initiated peer teaching. Asimilar practice was pointed by the literature on use of peer learning in the international context (Boud, 2001). For the international Universities, financial constraint lead to teachers' heavy workload but in Bhutanese context financial difficulty was not spelled out. To avoid forming groups each time peer teaching was initiated, the class sitting arrangement was made by the teacher in such a way that one high achiever was paired with one low achiever. There was no mention of students feeling intimidated with such arrangement. However, the teachers' role ended once the pair was formed and task was given. It was like the teacher did not exist after that. This finding was not in line with the other research where the teacher was very much present as a facilitator during the process (Sukrajh, 2018;Mustafa, 2017).

Reciprocal peer learning did take place in schools among students of almost same learning ability. However, it was not as widely practiced as peer teaching in the Bhutanese context. Similar findings were reported by other researchers (Brookfield and Preskill 1999 in Boud, 2001). In the Bhutanese schools, both the teachers and students were not aware of the terminology even. This could be due to the continual exposure of students to teacher-centered teaching where knowledge transferwas seenonly one way - from one who was all knowing to others who did not know.

Comfort zone is very important for effective learning to take place. The literature pointed the practice of peer learning in other context due to teachers' workload (Boud, Cohen \& Sampson, 1999). This was true for teacher initiated peer teaching. However, in the student initiated peer learning, the practicewas due to the existence of comfort zone. The 
comfort zone was minimal between a teacher and students, and quite high among students themselves. Students engaged in peer learning by forming their own grouping with friends they were comfortable with. They were even comfortable with class sitting partners formed by the teachers. Though teachers were aware that students hardly approached them for doubt clarification, interestingly the study did not point to them being aware that it could be due to existence of minimal comfort zone between them and students.

There were many reasons for students not feeling comfortable with teachers. Firstly, the teaching approach was mostly teacher centered that limited students' engagement in active learning. They became dependent learner. Similar practices were observed in most of the south east Asian countries (Loh and Teo, 2017). Secondly it was the type of language used in communication. Though in Bhutanese schools, the teaching was mostly in English, it is still a second language. With the teachers, students were expected to communicate in English but among friends, communication was in their local dialect and thus, the existence of high comfort zone. Thirdly, the teachers were accorded high respect making them seem unapproachable. Students feared to approach them least they were offended that students did not pay attention in the class or their questions were found to be silly. This was in line with the other studies (Loh and Teo, 2017; Kyong-Jee and Curtis, 2002)where the cultural belief and values had an impact on how students learn. Lastly, teachers were generally found to be strict with some resorting to use of corporal punishment that was banned in Bhutanese schools in 2008 .

Many of the schools, especially the boarding schools, had the practice of offering remedial classes. However, in the remedial classes, there was no real teaching. Instead, the students were made to carry out self study which was not what it was supposed to be. According to other studies, remedial classes were conducted to give additional opportunities in terms of use ofvaried teaching and learning materials, and approaches that catered to low achievers (Cheng, 2014) to bring about improved learning (Cheng, 2014; Jadal, 2012; Abu Armana, 2011; Luo, 2009).Also, in Bhutanese schools, remedial classes were supervised by a teacher on duty who was not necessarily teaching the low achievers which defeats the purpose if the teacher is from different subject background. In the present practice, there existed a notion that silence has to be maintained during remedial class. This was also observed in the hostel. Students were supposed to maintain silence discouraging any kind of learning among peers. This kind of practices limits learning from friends. The possibility of enhancing learning through peer is huge in remedial classes. At present most of the schools have not paid enough attention on using boarding facilities to encourage peer-learning. Schools have arranged the boarding facilities purely based on the reducing disciplinary cases.

With the world now being technology driven, there are opportunities to enhance learning through use of internet and social media (Yang and Chang, 2012). At present, boarders have limited access to internet. For day scholars, the use of social media in learning is more towards sharing information only. Peer learning can be enhanced using social media.

\section{CONCLUSION}

The existence of comfort zone is quite minimal between the students and teacher. As such teachers are looked upon as unapproachable, strict and some one to be feared. The use of corporal punishment by some teachers though not widely present, has not helped. In addition, the classroom use of language has further reduced the comfort zone. However, peer learning has come as a boon. It is widely used by the students and the teachers and it has positive effect on students' learning.

Boarding is a home away from home. At present most of the schools have not paid enough attention on using boarding facilities to encourage peer learning. Schools have arranged the boarding facilities purely based on the reducing disciplinary cases. Opportunities for schools to use boarding facilities to enhance students' academic learning are huge.

Many of the schools are concerned about students' learning and provides opportunities to low achievers to improve through conducting remedial classes. However, the present practice of organizing remedial classes need to be revisited. There medial classes offers possibility of enhancing students' learning through peer learning.

Though peer learning has led to students enhanced learning, understanding the multifaceted approach of practicing peer learning in various situation is required. As such, we recommend the following:

a. The comfort zone needs to be enhanced between the teacher and students if learning is to take place. The $\mathrm{MoE}$ and colleges of education need to work on either offering a professional development on how to maximise the comfort zone between a teacher and a student; 
b. Thecolleges of education could formalize and include the multifaceted approach of practicing peer learning in their teacher training programmes;

c. Theschools to encouraging peer learning in the boarding school as well as through remedial classes looking at best practices followed in other countries; and

d. Study could be carried out to find out the extent and intent of use of corporal punishment in the schools even after it has been banned in the Bhutanese schools as it has negative effect on students' learning.

\section{REFERENCES}

[1] Abu Armana, M. R. (2011). The Impact of a Remedial Program on English Writing Skills of the Seventh Grade Low Achievers at UNRWA Schools in Rafah. (AM thesis, The Islamic University of Gaza).

[2] Black et al. (2003). Assessment for learning: Putting it into practice. Buckingham, England: Open University Press.

[3] Black, P., \&Wiliam, D. (2005). Developing a theory of formative assessment. In Assessment and learning, edited by John Gardner, 81-100. London: Sage publications.

[4] Boud, D., Cohen, R., \& Sampson, J. (1999). Peer Learning and Assessment. Assessment and Evaluation in Higher Education, 24(4), 413-426.

[5] Boud, D. (2001). Making the move to peer learning. In Boud, D., Cohen, R. \& Sampson, J. (Eds.) (2001).Peer Learning in Higher Education: Learning from and with each other, London: Kogan Page(now Routledge), 1-20.

[6] Bulte, C., Betts, A., Garner, K. \& During, S. 2007. Student teaching: views of student near-peer teachers and learners. Medical Teacher. 29(6), 583-590.

[7] Cheng CM. "Individual Differences: How Remedial Teaching Transforms Low- Achievers When Learning English.” Journal of Modern Education Review. 2014; 4(11), 859-877. istep

[8] Froyd, J., \& Simpson, N. (2010). Student-centered learning addressing faculty questions about student-centered learning. Retrieved from file:///C:/Users/user/Downloads/7277Article\%20Text-29045-1-10-20120920.pdf

[9] Jadal M. M. (2012). "Developing skills of English through remedial package by low achievers at primary level", Journal of Arts and Culture, 3(2), 118-122

[10] Jaques, D. (2000). Learning in Groups, 3rd edn. London:

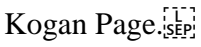

[11] Kyong-Jee, K., and Curtis J. B.( 2002) Cross-cultural Comparisons of Online Collaboration, Journal of ComputerMediated Communication, 8 (1), https://doi.org/10.1111/j.1083-6101.2002.tb00163.x

[12] Loh, C. Y. R. and Teo, T. C. (2017). Understanding Asian Students Learning Styles, Cultural Influence and Learning
Strategies. Journal of Education and Social Policy. 7(1), $194-$ 210.

[13] Luo Y. (2009). "The effect of using E-learning web sites as a remedial teaching aid on English underachievers at Universities of Science and Technology", Journal of Engineering Technology and Education, 6(2),182-195.

[14] Maxwell, T.W. 2008. Bhutan, The Greenwood Encyclopedia of Children's Issues Worldwide: Asia and Oceania, General Editor, Irving Epstein, Volume Editor, JyotsnaPattnaik, New York, Greenwood Press, 55-77. ISBN: 0-313-33620-2

[15] Mustafa, M.M. (2017). Learning with each other: Peer learning as an academic culture among graduate students in education. American Journal of Educational research, 5(9),944-951. DOI: 10.12691/education-5-9-3.

[16] Roder, D.C. (2012).Girls should come up: Gender and schooling in contemporary Bhutan (Doctoral dissertation, Arizona State University).

[17] Routman, R. (2005). Writing essentials: Raising expectations and results while simplifying teaching. Portsmouth, NH: Heinemann.

[18] Schuelka, M. \& Maxwell, T.W. (eds) (2016). Education in Bhutan: From the Buddhist monastery to Gross National Happiness education, Education in the Asia-Pacific Region: Issues, Concerns and Prospects Series, Springer, London.

[19] Sukrajh, V. (2018). The use of peer teaching to promote active learning amongst senior medical students. (Master thesis, Stellenbosch University).

[20] Topping, K. J. (2005). Trends in peer learning. Educational Psychology. 25(6), 631-645.

[21] Topping, K. J. (2009). Peer Assessment, Theory into Practice, 48(1), 20-27.

[22] Utha, K. (2015). Formative Assessment Practices in Bhutanese Secondary Schools and its impact on Quality of Education. (Doctoral dissertation, Aalborg University).

[23] Utha, K. et al. (2016). Quality of School Education in Bhutan: Case Studies in the Perspective of Gross National Happiness and Assessment Practices. Denmark: Aalborg University Press

[24] Wessel, A. (2015). Peer learning strategies in the classroom. Journal of Best Teaching practices. 2(1), 14-16.

[25] Yang, C., \& Chang, Y. S. (2012). Assessing the effects of interactive blogging on student attitudes towards peer interaction, learning motivation, and academic achievement. Journal of Computer Assisted learning, 28(20, 126135.doi.1111/j.1365-2729.2011.0042 